\title{
DETERMINAÇÃO DOS NÍVEIS SÉRICOS DE PROTEÍNA C- REATIVA (CRP) EM CÃES COM ALTERAÇÕES DOS PARÂMETROS HEMATOLÓGICOS
}

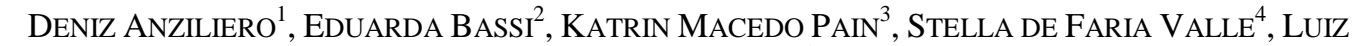 \\ CARLOS KREUTZ ${ }^{5}$ \\ ${ }^{1}$ Pós-Graduando em Medicina Veterinária, Universidade Federal de Santa Maria, Santa Maria, RS, Brasil. \\ anzziliero@yahoo.com.br \\ ${ }^{2}$ Farmacêutica Bioquímica, DB Diagnósticos do Brasil, Passo Fundo, RS, Brasil. \\ ${ }^{3}$ Médica Veterinária autônoma, Caxias do Sul, RS, Brasil. \\ ${ }^{4}$ Professora Doutora da Universidade Federal do Rio Grande do Sul, Porto Alegre, RS, Brasil. \\ ${ }^{5}$ Professor PhD da Universidade de Passo Fundo, Passo Fundo, RS, Brasil.
}

\begin{abstract}
RESUMO
O sistema imune natural responde ao processo infeccioso ou inflamatório produzindo uma série de proteínas inflamatórias, com atividade inespecífica, denominadas de proteínas de fase aguda, entre as quais se destaca a Proteína C-Reativa (CRP). O presente estudo teve como objetivo investigar a correlação entre as alterações dos parâmetros hematológicos em cães e a presença de CRP na circulação sanguínea. Amostras de sangue de 70 cães atendidos em um Hospital Veterinário Universitário foram submetidas ao hemograma e à quantificação da CRP; em um segundo momento, amostras de sangue de cães inoculados experimentalmente com uma suspensão inativada de Micrococcus luteus (ATCC 7468) foram submetidas a mesma avaliação. De acordo com os parâmetros hematológicos e a presença ou não de CRP, pode-se classificar os animais em cinco grupos distintos: grupo A) cães negativos para a CRP e hemograma normal; grupo B) cães positivos para a CRP e hemograma normal;

grupo C) cães positivos para a presença de CRP e hemograma alterado (neutrofilia e leucocitose); grupo D) cães positivos para a CRP, com neutrofilia; grupo E) cães positivos para a CRP e leucopenia. Cães inoculados experimentalmente com $M$. luteus apresentaram um aumento significativo na concentração de CRP, entre 24 e 48 horas após inoculação, com um decréscimo nas concentrações gradativamente até o $10^{\circ}$ dia. Nesses animais, observou-se uma discreta neutrofilia e leucocitose coincidindo com o pico nos valores da CRP. Baseado nos resultados acima, concluiu-se que a determinação da presença da CRP em cães pode ser utilizada como uma importante ferramenta no diagnóstico veterinário. Haja vista a rapidez com que o teste é executado, o baixo custo e a necessidade de pequena quantidade de amostras, a utilização da CRP pode auxiliar o monitoramento da evolução de um processo infeccioso/inflamatório.
\end{abstract}

PALAVRAS-CHAVE: diagnóstico; inflamação; hemograma; proteínas de fase aguda.

\section{SERUM C-REACTIVE PROTEIN (CRP) MEASUREMENT IN DOGS WITH ALTERED HEMATOLOGICAL PARAMETERS}

\section{ABSTRACT}

The natural immune response to infectious agents is partially mediated by a group of proteins named acute phase proteins; one of the major and most important proteins from the acute phase is the C-Reactive Protein (CRP). The aim of the present study was to investigate the correlation between alterations on white blood cell counts (WBC) and the presence of circulating CRP. Blood samples from 70 dogs were submitted to hematological examination and detection of CRP; in addition, blood samples from 12 dogs experimentally inoculated with an inactivated sample of Micrococcus luteus (ATCC 7468) were also analyzed. According to the hematological parameters and CRP values, the samples were classified in 5 different groups: group A) dogs without CRP and 
normal WBC; group B) dogs with elevated levels of CRP but normal WBC; group C) dogs with elevated CRP values and altered WBC (neutrophilia and leukocytosis); group D) dogs with both CRP and increased neutrophils values; and group E) dogs with elevated CRP values but with leukopenia. Dogs experimentally inoculated with $M$. luteus had a significant and promt increase in CRP values between 24 and $48 \mathrm{hr}$ p.i., which declined up to the $10^{\text {th }}$ day when the experiment was completed. In these dogs, a discrete neutrophilia and leukocytosis was observed coincidently with the CRP elevation. Thus, it can be suggested that the detection of CRP in the blood of dogs should be used as an indication of an infection or inflammation and, because of the low amount of blood needed, low cost and easiness to perform the test, monitoring CRP levels might be useful to evaluate the recovery from an infection disease.

KEYWORDS: acute phase proteins; blood cell count; diagnosis; inflammation.

\section{INTRODUÇÃO}

A resposta de fase aguda consiste em uma resposta do organismo, complexa e não específica que, em geral, se desenvolve e termina rapidamente logo após alguma injúria tecidual (MURATA et al., 2004). A origem desse mecanismo pode ser atribuída a uma resposta imunológica, infecciosa, neoplásica, ou traumática (MURATA et al., 2004; PEPYS \& HIRSCHFIEL, 2003; CERÓN et al., 2005). A resposta de fase aguda é considerada parte da resposta imune natural de defesa do organismo, responsável pela sobrevivência do hospedeiro durante a fase crítica e precoce, decorrente da exposição a diferentes microorganismos (MURATA et al., 2004; PETERSEN et al., 2004; CERÓN et al., 2005).

As alterações sistêmicas da fase aguda, no decorrer do processo inflamatório, incluem febre, elevação no número de leucócitos circulantes, alterações dos níveis de cortisol sanguíneos e variações nas concentrações plasmáticas, de um grupo de proteínas denominadas de proteínas de fase aguda (MARTÍNEZ-SUBIELA et al., 2001; CECILIANI et al., 2002). As proteínas de fase aguda (PFA) são classificadas segundo suas caraterísticas regulatórias positivas ou negativas, quando consideradas as concentrações detectadas na corrente sanguínea do organismo (MURATA et al., 2004). No grupo de proteínas com característica regulatória negativa, estão classificadas a albumina e a transferina. Já as PFA de caráter positivo são classificadas como glicoproteínas, sintetizadas essencialmente pelos hepatócitos no fígado, sob a ação de citocinas próinflamatórias. Nesse grupo, estão inseridas a hepatoglobina, a proteína sérica amilóide A, ceruloplasmina, glicoproteína alfa-1-ácido, o fibrinogênio e a Proteína C-reativa (MURATA et al., 2004; EKERSALL et al., 2011). Dentre essas proteínas, destaca-se principalmente a Proteína C-
Reativa (CRP), sintetizada no fígado sob influência de citocinas como o fator de necrose para tumores (TNF), interferon- $\gamma$ (INF- $\gamma$ ) e das interleucinas 1 (IL-1) e 6 (IL-6), que são produzidas por um grupo restrito de células, principalmente pelos macrófagos em resposta a estímulos externos (CERÓN et al., 2005). A CRP pertence à família das pentraxinas e tem se mostrado uma forte indicadora da inflamação e/ou infecção na Medicina Veterinária (RIKIHISA et al., 1994; YAMAMOTO et al., 1994; HAYASHI et al., 2001; SHIMADA et al., 2002; EKERSALL $\&$ BELL, 2010). A CRP tem um importante papel na interação entre a resposta imune intata e específica, atuando na opsonização, interação com receptores específicos da fagocitose, ativação da via clássica do complemento, síntese de citocinas e, por fim, atuando na regulação da resposta imunológica do hospedeiro (DU CLOS \& MOLD, 2001). Por outro lado, as citocinas geradas durante o processo inflamatório/infeccioso fornecem diferentes estímulos à medula óssea, alterando os parâmetros hematológicos, os quais são pontoschave para avaliar a presença ou não de infecções na clínica veterinária, principalmente em pequenos animais (JAIN et al., 2011).

No diagnóstico veterinário, a confecção do hemograma necessita, invariavelmente, de amostras coletadas adequadamente e que apresentem excelente padrão de qualidade, evitando-se, assim, a geração de resultados inconsistentes e duvidosos. Nesse processo, são necessárias quantidades significativas e frequentes de sangue ( 1 a $3 \mathrm{~mL}$ ) e total ausência de fibrina, o que nem sempre se torna viável ou possível de se obter, principalmente em animais de raças pequenas e/ou de temperamento agressivo. Nesses casos, a utilização de outros biomarcadores do processo infeccioso e/ou inflamatório, mais rápidos, práticos e de reduzido custo, assumem um papel fundamental para a elaboração tanto de um 
diagnóstico, como para o prognóstico e monitoramento de terapias antimicrobianas em cães (EKERSALL \& BELL, 2010). Até o presente momento, a literatura ainda é escassa e/ou inconsistente sobre a interação entre as alterações nos parâmetros hematológicos e a presença das PFA, principalmente da Proteína C-Reativa (BURTON et al., 1994).

Atualmente, no Brasil, não há kits disponíveis específicos para a espécie canina passíveis de serem utilizados na detecção da Proteína C-Reativa e, considerando as dificuldades de importação desse tipo de material, seja pelas restrições alfandegárias e/ou pelo elevado custo, a utilização dessa ferramenta torna-se inviável, principalmente nas clínicas veterinárias do país. $\mathrm{Na}$ última década, a comunidade científica internacional, através de uma forte corrente, vem demonstrando a possibilidade da utilização de reagentes heterólogos, principalmente os utilizados para humanos, para a detecção da CRP em cães. Nesses estudos, a Proteína C-Reativa é mensurada por técnicas automatizadas como a imunoturbidimetria, amplamente utilizada em humanos e, mais recentemente, por meio de ensaios imunoenzimático e kits de CRP altamente sensíveis (KJELGAARD-HANSEN et al., 2003; FRANSSON et al., 2007; MUNHOZ et al., 2009; KLENNER et al., 2010; PAIN et al., 2013). Considerando que a grande maioria dos hospitais veterinários e, principalmente, as clínicas veterinárias brasileiras não possuem a estrutura e os equipamentos necessários para a realização dessas técnicas, e a disponibilidade de uma técnica rápida e de baixo custo poderia auxiliar consideravelmente tanto no diagnóstico de infecções, como no prognóstico e acompanhamento do tratamento em cães.

Assim, o objetivo do presente estudo foi avaliar a presença e a cinética de atuação da CRP, por meio da técnica de aglutinação em látex e sua possível associação com alterações hematológicas em caninos, visando, assim, difundir a ideia da sua utilização como um método auxiliar na determinação de processos inflamatórios e monitoramento terapêutico.

\section{MATERIAL E MÉTODOS}

O presente estudo foi dividido em duas etapas. A primeira etapa foi conduzida para testar a hipótese de associação entre as duas técnicas. Foram então utilizadas 70 amostras de sangue obtidas de cães, pacientes do Hospital Veterinário da Universidade de Passo Fundo, UPF-RS. As amostras foram remetidas ao laboratório de Patologia Clínica para realização de exames de hemograma e bioquímica sérica e, posteriormente, foram usadas para a detecção e quantificação da CRP. Os resultados obtidos dos testes hematológicos, a partir do hemograma, foram comparados quanto à presença e quantidade da CRP.

$\mathrm{Na}$ segunda etapa, doze cães sem raça definida (machos e fêmeas) do Biotério Central da Instituição, previamente testados, e que apresentavam hemograma sem alterações e resultado negativo para CRP os animais foram inoculados, por via intramuscular, com um antígeno bacteriano (Micrococcus luteus ATCC 7468, $1 \mathrm{~mL}$, densidade óptica de 0,5/OD $\mathrm{OD}_{49 \mathrm{~nm}}$ ), inativado pelo calor a $60^{\circ} \mathrm{C}$ por $30 \mathrm{~min}$, com o objetivo de induzir uma resposta inflamatória. Amostras de sangue foram coletadas com intervalos de 2 a 3 dias para a determinação dos parâmetros hematológicos e da Proteína C-Reativa por um período de 10 dias.

$\mathrm{O}$ presente trabalho foi realizado em conformidade com as normas do COBEA e de acordo com o Comitê de ética em Pesquisa - CEP na época de realização do estudo.

As amostras foram coletadas em tubos com e sem EDTA para realização do hemograma e da CRP, respectivamente. $\mathrm{O}$ hemograma foi realizado por método automatizado e a contagem diferencial de leucócitos foi obtida por meio de esfregaços sanguíneos corados pelo método panótico rápido (WEISS \& TVEDTEN, 2004), seguido da contagem diferencial em microscópio ótico (1000X), utilizando-se como referência valores previamente citados na literatura (MEDÁILLE et al., 2006; BECKER et al., 2008).

A presença e quantificação da CRP foram feitas utilizando-se um kit de aglutinação em látex ${ }^{\mathrm{a}}$, utilizado em humanos, segundo recomendações do fabricante (In Vitro Diagnóstica, S/A): amostras de soro $(25 \mu \mathrm{L})$ foram misturadas em igual volume do reagente sobre uma placa de vidro. A ocorrência de uma nítida aglutinação foi indicativa da presença de CRP na concentração mínima de $6 \mu \mathrm{g} / \mathrm{mL}$ (limite inferior de sensibilidade para soro humano); controles positivos e negativos foram utilizados durante os testes. Em seguida, as amostras positivas foram diluídas seriadamente (fator 2) em solução salina (0,9\%; diluições de 1:2 a 1:256, equivalente a 
concentrações séricas de 12 a $1536 \mu \mathrm{g} / \mathrm{mL}$, respectivamente) para determinar a quantidade de CRP nas amostras de soro.

Para testarmos a hipótese da existência de correlação entre os dois testes os dados da CRP e do hemograma foram tabulados e submetidos à análise estatística pela equação de Pearson para a determinação do coeficiente de correlação seguido da existência de concordância entre os testes pelo teste do coeficiente Kappa.

\section{RESULTADOS E DISCUSSÃO}

Com os resultados obtidos na primeira etapa do estudo, foi identificada uma associação entre alterações nos parâmetros hematológicos e a presença ou não de CRP, sendo os animais classificados em cinco grupos distintos: grupo A) cães negativos para a CRP e hemograma normal; grupo B) cães positivos para a CRP e hemograma normal; grupo C) cães positivos para a presença de CRP e hemograma alterado (neutrofilia e leucocitose); grupo D) cães positivos para a CRP, com neutrofilia; grupo E) cães positivos para a CRP e leucopenia (Tabela 1).

$\mathrm{Na}$ segunda etapa do experimento, pode-se observar que os cães inoculados experimentalmente com o M. luteus apresentaram um pico nos níveis da Proteína C-Reativa entre 24 a 48 hpi, valores que foram decrescendo rapidamente nos dias subsequentes à inoculação (Figura 1). É interessante observar que o pico de CRP coincidiu com uma discreta leucocitose seguida de neutrofilia (Figura 2). No entanto, observou-se que os níveis séricos de CRP aumentam ou diminuem com mais intensidade e mais rapidamente que as discretas alterações do hemograma.

Tabela 1. Relação entre os parâmetros do hemograma e da concentração sérica de Proteína C-reativa (CRP; $\mu \mathrm{g} / \mathrm{mL}$ ) em cães (machos e fêmeas) atendidos no Hospital Veterinário, classificados em cinco grupos distintos, de acordo com os resultados do hemograma e da concentração de CRP

\begin{tabular}{lcccc}
\hline Grupo & $\mathrm{n}$ & $\begin{array}{c}\text { Proteína C- } \\
\text { reativa } \\
(\mu \mathrm{g} / \mathrm{mL})\end{array}$ & $\begin{array}{c}\text { Neutrófilos } \\
\text { Intervalo de referência* } \\
(3000-11500)\end{array}$ & $\begin{array}{c}\text { Leucócitos totais } \\
\text { Intervalo de referência } \\
(6000-17000)\end{array}$ \\
\hline $\mathrm{A}$ & 11 & Negativa** $^{* *}$ & $3786-11130$ & $6650-14752$ \\
$\mathrm{~B}$ & 28 & $6,0-768,0$ & $3168-10959$ & $6060-16860$ \\
$\mathrm{C}$ & 22 & $12,0-1536,0$ & $12372-50406$ & $17280-69773$ \\
$\mathrm{D}$ & 6 & $12,0-384,0$ & $11860-14201$ & $13500-16310$ \\
$\mathrm{E}$ & 3 & $6,0-768,0$ & $878-4283$ & $4360-5160$ \\
\hline
\end{tabular}

${ }^{\mathrm{A}} \mathrm{CRP}$ negativa e hemograma normal; ${ }^{\mathrm{B}} \mathrm{CRP}$ positiva e hemograma normal; ${ }^{\mathrm{C}} \mathrm{CRP}$ positiva e hemograma alterado (neutrofilia e leucocitose); ${ }^{\mathrm{D}} \mathrm{CRP}$ positiva e neutrofilia; ${ }^{\mathrm{E}} \mathrm{CRP}$ positiva e leucopenia; ${ }^{\mathrm{n}}$ número de amostras. $* \mathrm{n} \% \mu \mathrm{l}$ - WEISS \& TVEDTEN (2004); $* *(\mathrm{CRP}<6 \mu \mathrm{g} / \mathrm{mL})$.

A resposta temporal da CRP à inoculação do $M$. luteus foi similar àquela observada anteriormente para a infecção com Bordetella bronchiseptica (YAMAMOTO et al., 1994) ou pela administração intramuscular (IM) de caseína (PARRA et al., 2005), porém muito mais rápida do que a observada quando da infecção experimental por Ehrlichia canis (RIKIHISA et al., 1994; SHIMADA et al., 2002) ou Trypanossoma brucei (NDUNG'G et al., 1991). Essa diferença temporal deve-se principalmente à natureza do antígeno inoculado; tanto o inóculo inativado de $M$. luteus ou a inoculação IM de caseína (PARRA et al., 2005), quanto à infecção ativa com B. bronchiseptica (YAMAMOTO et al., 1994) permanecem no exterior das células (antígenos exógenos) e são reconhecidos imediatamente pelos macrófagos, gerando o estímulo necessário para a secreção de CRP; por outro lado, o desafio por $E$. canis e o $T$. brucei replicam-se lentamente no interior das células fagocíticas, principalmente monócitos e macrófagos, e o estímulo para produção de citocinas pró-inflamatórias indutoras de CRP somente ocorre após a liberação de grande quantidade de microorganismos na corrente sanguínea. Não obstante, a constituição da parede celular dos microorganismos apresenta características peculiares, com presença maior, menor ou com ausência de lipopolissacarídeos e, consequentemente, resultando em formas distintas de estimulação dos macrófagos e, logo, das citocinas responsáveis pela mediação da produção de CRP. 


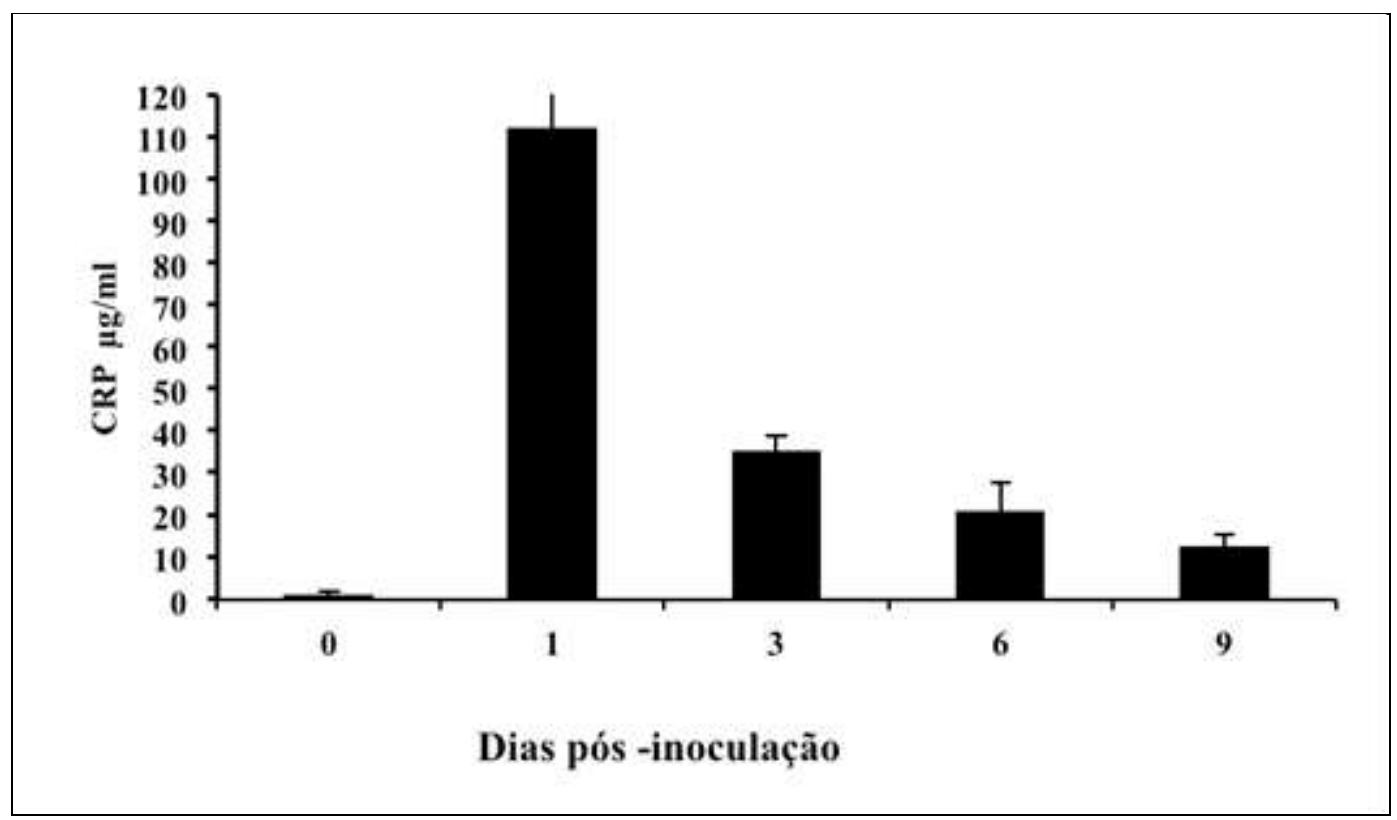

Figura 1. Resposta temporal da Proteína C-Reativa (CRP) à estimulação antigênica. Amostras de sangue foram previamente coletadas para determinação dos valores séricos de CRP (dia 0). Após a inoculação intramuscular com uma suspensão inativada de Micrococcus luteus (ATCC 7468), as amostras foram coletadas em dias alternados, para a determinação da CRP.

Devido aos diferentes métodos utilizados para determinação da Proteína C-Reativa, não é possível estabelecer uma relação fiel entre a quantidade $(\mu \mathrm{g} / \mathrm{mL})$ de CRP detectada nos diferentes estudos, principalmente devido ao fato de o método utilizado no presente trabalho (aglutinação em látex) apresentar sensibilidade inferior ao teste imunoenzimático (ELISA) e/ou ao ensaio de imunoturbidimetria, frequentemente utilizado nos demais estudos (NDUNG'G et al., 1991; RIKIHISA et al., 1994; SHIMADA et al., 2002; PARRA et al., 2005). No entanto, em relatos utilizando antígeno bacteriano infeccioso (B. bronchiseptica), os níveis médios detectados $(498 \pm 132 \mu \mathrm{g} / \mathrm{mL})$ foram ligeiramente superiores, enquanto que a infecção por E. canis (pico de $40 \mu \mathrm{g} / \mathrm{mL}$ ) e a inoculação de caseína (média de 44,89 $\mu \mathrm{g} / \mathrm{mL}$ ) induziram níveis séricos de CRP muito abaixo do pico detectado nesta amostragem (192 $\mu \mathrm{g} / \mathrm{mL})$. Além disso, deve-se considerar que, no presente estudo, utilizou-se inóculo inativado, em comparação com os inóculos infecciosos de $B$. bronchiseptica (YAMAMOTO et al., 1994) e E. canis (RIKIHISA et al., 1994; SHIMADA et al., 2002) ou T. brucei (NDUNG'G et al., 1991).

Ao se comparar os níveis séricos de CRP de cães do grupo $\mathrm{C}$ e $\mathrm{D}$, notou-se que um processo infeccioso ativo induz níveis séricos de CRP similar ao da infecção experimental por B. bronchiseptica (YAMAMOTO et al., 1994), independentemente da sensibilidade do teste utilizado. E mais, cães com diversos quadros clínicos patológicos (Leishmaniose, piometra, sepse, tumor mamário, entre outros) apresentaram níveis séricos de CRP que variaram de 29,98 a $1536 \mu \mathrm{g} / \mathrm{mL}$; por outro lado, cães considerados sadios apresentaram níveis séricos de CRP entre 0,0 e 3,47 $\mu \mathrm{g} / \mathrm{mL}$ (PARRA et al., 2005; BASSO et al., 2007), níveis que não poderiam ser detectados no presente experimento devido à sensibilidade do teste utilizado. Não obstante, foi demonstrada uma correlação positiva significativa entre a detecção da CRP por ambos os métodos (aglutinação em látex e ELISA), conforme descrito por VEIGA et al. (2009).

No presente trabalho, foi encontrada uma correlação positiva forte entre os resultados da CRP e o hemograma (leucocitose e neutrofilia) $(p=0,77$ e $\mathrm{p}=0,93$, respectivamente). Quando testados os valores de concordância entre ambos os testes, foi encontrado um valor Kappa de 0,53, considerado moderado. Assim, os dados do presente trabalho nos permitem afirmar que a utilização do método de aglutinação em látex poderia ser utilizado como uma alternativa no monitoramento do processo infeccioso e na orientação de procedimentos terapêuticos. 


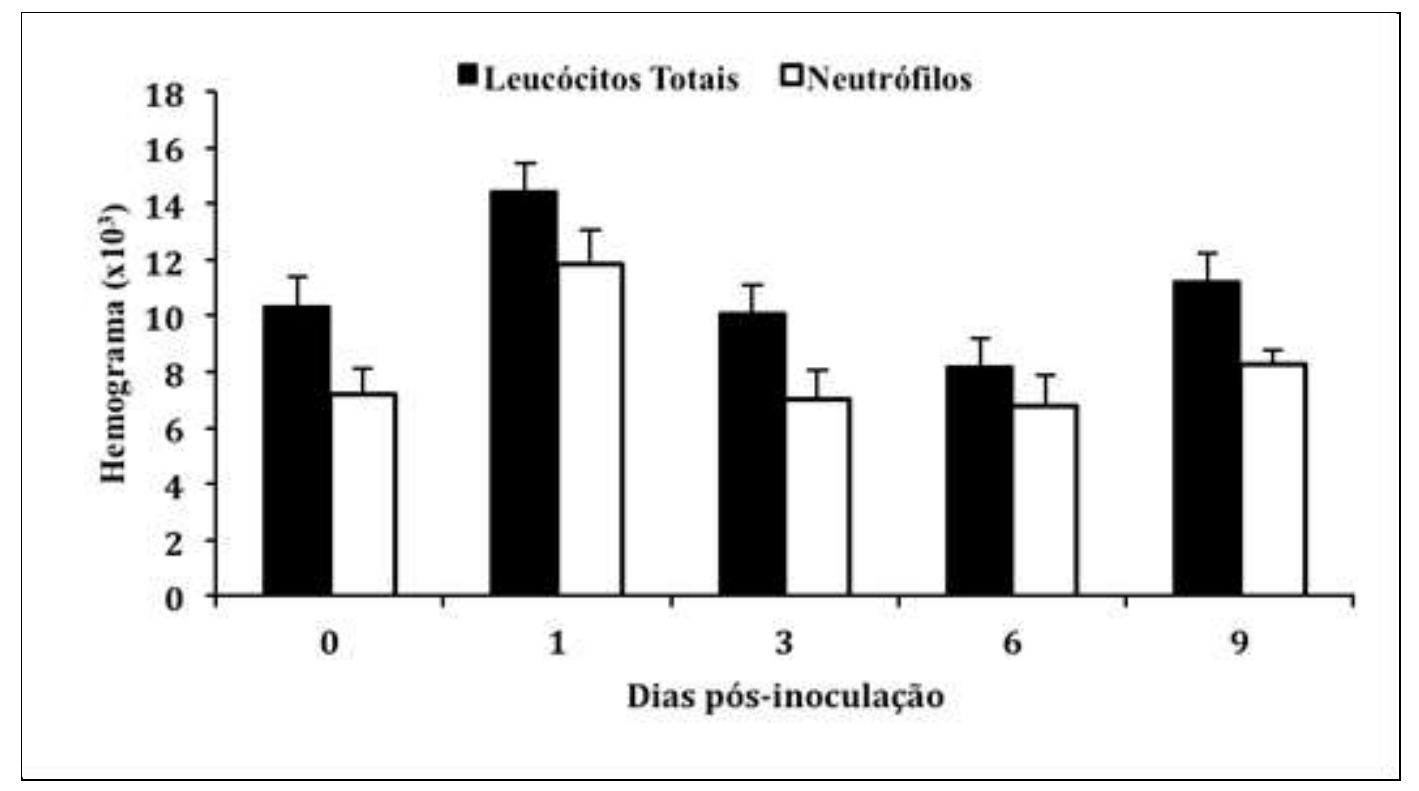

Figura 2. Variações da contagem de Leucócitos totais e neutrófilos $\left(1 \times 10^{3} / \mu 1\right)$ em cães inoculados com uma suspensão inativada de Micrococcus luteus (ATCC 7468). Amostras de sangue foram coletadas para determinação dos parâmetros hematológicos anteriormente à inoculação (dia 0) e após à inoculação.

A rápida variação (aumento e diminuição) dos níveis de CRP detectada nos cães experimentalmente inoculados com $M$. luteus devese ao fato de a CRP ser induzida imediatamente e tão somente em resposta às citocinas pró-inflamatórias TNF, IL-1 e IL-6, as quais, são produzidas em grandes quantidades pelos macrófagos em resposta a antígenos (JAIN et al., 2011). Esses níveis, quando da estimulação das citocinas, podem aumentar em níveis de 100 a 1000 vezes aos valores basais. Por outro lado, a proteína C-reativa tem meia-vida curta na circulação sanguínea e sua produção é prontamente interrompida quando cessa o estímulo antigênico - remoção do foco infeccioso (EKERSALL \& BELL, 2010). Em contraste, a resposta da medula óssea às citocinas é mais lenta $\mathrm{e}$ seus efeitos, obviamente, estendem-se por um período de tempo maior, devido à meia-vida relativamente longa dos leucócitos, o que é traduzido pela leucocitose e neutrofilia (WEISS \& TVEDTEN, 2004), geralmente observados em cães com um processo infeccioso em fase de resolução. De fato, observando-se os resultados da determinação da CRP e do hemograma dos cães analisados nesse experimento, fica evidente que os cães do grupo B (CRP positiva/ hemograma normal) encontravam-se no início de um processo infeccioso, ou processo infeccioso discreto, como aquele observado pela inoculação do $M$. luteus, porém não detectado ainda pela leitura do hemograma. Os cães dos Grupos C e
D (CRP alterada e leucocitose e/ou neutrofilia) encontravam-se visivelmente com um processo infeccioso/inflamatório em andamento ou em fase de resolução, respectivamente. Finalmente, os dados dos animais do grupo E sugerem o início de uma possível infecção viral, indicada no diagnóstico clínico (comunicação pessoal - dados não mostrados).

A intensa resposta detectada para a CRP, aliada à leucopenia, foi recentemente demonstrada em trabalhos experimentais com parvovirose canina, em que a CRP apresenta-se como um forte biomarcador e excelente indicativo do prognóstico de infeções (GODDARD et al., 2008; KOKATURK et al., 2010). De fato, essas interpretações são condizentes com o quadro clínico de cada animal, conforme dados obtidos das fichas de requisições dos exames hematológicos.

\section{CONCLUSÃO}

A detecção da CRP no soro de cães é um claro indicativo da presença de um processo infeccioso e/ou inflamatório no animal. A cinética da CRP consiste em uma resposta intensa, rápida e principalmente de curta duração. Dependendo do estágio do processo infeccioso e/ou inflamatório, o pico nos níveis da CRP no sangue pode ser observado juntamente com alterações hematológicas (leucocitose, neutrofilia e, nos casos de infecções 
virais, leucopenia). A determinação da CRP não dispensa a realização do hemograma; no entanto, a avaliação da presença ou não da CRP pode ser uma importante ferramenta no acompanhamento da evolução de um processo infeccioso e/ou inflamatório, auxiliando no prognóstico de mortalidades. A aglutinação em látex pode ser executada rapidamente com uma quantidade significativamente menor de amostra e, consequentemente, pode ser determinada com maior frequência. A técnica é de fácil execução, dispensa equipamentos sofisticados, ausentes nas clínicas veterinárias, e, principalmente, tem custo significativamente reduzido - em torno de um real, se comparado com os demais exames utilizados corriqueiramente nos laboratórios de Patologia Clínica Veterinária.

\section{FONTES DE AQUISIÇÃO}

${ }^{a}$ In vitro Diagnóstica S/A, Itabira, MG

\section{REFERÊNCIAS}

BASSO, P.C.; RIVERA, F.B.; ANZILIERO, D.; MELATTI, L.; BARCELLOS, H.H.A.; BRUN, M.V. Validação dos critérios de sepse em cães com piometra. Revista Científica de Medicina Veterinária - Medvep, Pequenos animais e animais de estimação, n.5, p. 106109, 2007.

BECKER, M.; MORITZ, M.; GIGER, U. Comparative clinical study of canine and feline total blood cell count result with sevem in-clinic and two comercial laboratory hematology analyzers. Veterinary Clinical Pathology, v.37, p.373-484, 2008.

BURTON, S.A.; HONOR, D.J, MACKENZIE, A.L.; ECKERSALL, P.D, MARKHAM, R.J, HORNEY, B.S. C-Reactive protein concentration in dogs with inflammatory leukograms. American Journal of Veterinary Research, v. 55, p. 613-618, 1994.

CECILIANI, F.; GIORDANO, A.; SPAGNOLO, V. The systemic reaction during inflammation: the acute-phase proteins. Protein \& Pepetide Letters, v.9, p.211-223, 2002.

CERÓN, J.J.; ECKERSALL, P.D.; MATÍNEZSUBIELA, S. Acute phase proteins in dogs and cats: current knowledge and future perspectives. Veterinary Clinical Pathology, v.34, n.2, p. 85-99, 2005.

DU CLOS, T.W.; MOLD, C. The role of C-reactive protein in the resolution of bacterial infection. Current Opinion in Infectious Diseases, v.14, p.289-293, 2001.

ECKERSALL, P.D.; BELL, R. Acute phase proteins: Biomarkers of infection and inflammation in veterinary medicine. The Veterinary Journal, v.185, p.23-27, 2010.
FRANSSON, B.A.; BERGSTROM, A.; WARDROP, K.J.; HAGMAN, R. Assessment of three automated assays for C-reactive protein determination in dogs. American Journal of Veterinary Research, v.68, p.1281-1286, 2007.

GODDARD, A.; LEISEWITZ, A.L.; CHRISTOPHER, M.M.; DUNCAN, N.M. \& BECKER, P.J. Prognostic usefulness of blood leukocyte changes in canine parvoviral enteritis. Journal of Veterinary Internal Medicine, v. 22, p.309-316, 2008.

JAIN, S.; GAUTAN, V.; NASEEM, S. Acute phase proteins: a diagnostic tool. Journal of Pharmacy and Biollied Sciences, v. 3, p. 118-127, 2011.

HAYASHI, S.; JINBO, T.; IGUCHI, K.; SHIMIZU, M.; SHIMADA, T.; NOMURA, M.; ISHIDA, Y.; YAMAMOTO, S. A comparison of the concentration of C-reactive protein and $\alpha 1$-acid glycoprotein in the serum of young dogs with acute inflammation. Veterinary Research Communication, v.25, p.117-120, 2001.

KLENNER, S.; BAUER, N.; MORITZ, A. Evaluation of three automated human immunoturbidimetric assays for the detection of C-reactive protein in dogs. Journal of Veterinary Diagnostic Investigation, v. 22, p.544-552, 2010.

KJELGAARD-HANSEN, M.; JENSEN, A.L.; KRISTENSEN, A.T. Evaluation of a Commercially Available Human C-Reactive Protein (CRP) Turbidometric Immunoassay for Determination of Canine Serum CRP Concentration. Veterinary Clinical Pathology, v.32, p.81-87, 2003.

KOCATURK, M.; MARTINEZ, S.; ERALP, O.; TVARIJONAVICIUTE, A.; CERON, J.; YILMA, Z. Prognostic value of serum acute-phase proteins in dogs with parvoviral enteritis. Journal of Small Animal Practice, v. 51, p. 478-483, 2010.

MARTÍNEZ-SUBIELA, S.; TECLES, F.; PARRA, M.D.; CERON, J.J. Acute phase proteins: general concepts and main clinical applications in veterinary medicine. Anales de Veterinaria de Murcia, v.17, p. 99-116, 2001.

MEDÁILLE, C.; BRIEND-MARSHAL, A.; BRAUM, J.P. Stability of selected hematology variables in canine blood kept at room temperature in EDTA for 24 and 48 hours. Veterinary Clinical Pathology, v.35, p.18-23, 2006.

MUNHOZ, T.D.; FARIA, J.L.M.; HERNANDES, G.V.; JOÃO, C.F.; PEREIRA, W.A.B.; ANDRÉ, M.R.; MACHADO,R.Z.; TINUCCI-COSTA, M. Mensuração da proteína c-reativa na infecção experimental por Ehrlichia canis (amostra Jaboticabal) e após o tratamento com cloridrato de doxiciclina em cães. Veterinária Notícias, v.15, p.65-79, 2009.

MURATA, H.; SHIMADA, N.; YOSHIOKA, M. Current research on acute phase proteins in veterinary diagnosis: an overview. The Veterinary Journal, v. 168, p. 28-40, 2004. 
NDUNG'U, J.M.; ECKERSALL, P.D.; JENNINGS, F.W. Elevation of the acute phase proteins in dogs infected with Trypanossoma brucei. Acta Tropica, v.49, p. 77-85, 1991.

PAIM, F.C.; DA SILVA, A.S.; PAIM , C.B.V.; FRANÇA, R.T.; COSTA, M.C.; DUARTE, M.M.M.F.; DA SILVA, C.A.; MAZZANTI, C.M.A.; MONTEIRO, S.G.; LOPES, S.T.A. Serum proteinogram, acute phase proteins and immunoglobulins in dogs experimentally infected with Rangelia vitalii. Veterinary Parasitology, v.192, p.137-142, 2013.

PARRA, M.D.; TECLES, F.; MARTÍNEZ-SUBIELA,S.; CERÓN, J.K. C-reactive protein measurement in canine saliva. Journal of Veterinary Diagnostic Investigation, v.17, p.139-144, 2005.

PEPYS, M.B.; HIRSCHFIELD, G.H. C-reactive protein: a critical update. The Journal of Clinical Investigation, v. 111, p.1805-1812, 2003.

PETERSEN, H.H.; NIELSEN, J.P.; HEEGAARD, P.M.H. Application of acute phase protein measurements in veterinary clinical chemistry. Veterinary Research, v.35, p. 163-187, 2004.

RIKIHISA, Y.; YAMAMOTO, S.; KWAK, I.; IQBAL, Z.; KOCIBA, $\quad$ G.; $\quad$ MOTT, J.; CHICHANASIRIWITHAYA, W. C-reactive protein and a1-acid glycoprotein levels in dogs infected with Ehrlichia canis. Journal of Clinical Microbiology, v. 32, p. 912-917, 1994.

SHIMADA, T.; ISHIDA, Y.; SHIMIZU, M.; NOMURA, M.; KAWATO, K.; IGUCHI, K.; JINBO, T. Monitoring C-reactive Protein in Beagle dogs experimentally inoculated with Ehrlichia canis. Veterinary Research Communication, v. 26, p.171-177, 2002.

VEIGA, A.P.M.; de OLIVEIRA, S.T.; ESTEVES, V.; PORTELA, V.M.; dos SANTO, A.P.; GONZÁLES, F.H.D. Utilização de técnica rápida de aglutinação em látex para determinação semiquantitativa dos níveis séricos de proteína $\mathrm{C}$ reativa em cães. Acta Scientiae Veterinariae, v.37, p.151-155, 2009.

YAMAMOTO, S.; SHIDA, T.; HONDA, M.; ASHIDA, Y.; RIKIHISA, Y.; ODAKURA, M.; HAYASHI, S.; NOMURA, M.; ISAYAMA, Y. Serum C-reactive protein and immune response in dogs inoculated with Bordetella bronchiseptica (phase I cells). Veterinary Research Communication, v.18, p.347-357, 1994.

WEISS, D.; TVEDTEN, H. The complete blood count and bone marrow examination: general comments and selective techniques. In: WILLARD, M. D. \& TVEDTEN, $H$. Small animal clinical diagnosis by laboratory methods. 4. ed. St. Louis, Missouri: Saunders, 2004. Cap. 2, p.14-37. 